\title{
Response to: The association between retinal thickness variations and restless leg syndrome (RLS)
}

\author{
Hatice Kose Ozlece ${ }^{1} \cdot$ Volkan Solmaz $^{2} \cdot$ Sadık Altan Özal ${ }^{3} \cdot$ Yahya Çelik $^{4}$
}

Received: 30 November 2018 / Revised: 12 June 2019 / Accepted: 14 June 2019 / Published online: 13 July 2019

(C) Springer Nature Switzerland AG 2019

\section{Dear Editor,}

We thank Dr. Lorenzo Ferro Desideri et al. for their comments. As we stated in our study, we performed a complete ophthalmological examination, including best corrected visual acuity (BCVA), ocular tonometry, slit-lamp, and fundus examination. However, as the measurements were in the normal range, they were not mentioned in the text.

And also we have determined the exclusion criteria as mentioned in the main text. The exclusion criteria were as follows: having comorbid diseases which can cause RLS or be confused with RLS like diabetes mellitus, polyneuropathy, lumbosacral radiculopathy, iron deficiency anemia, or thyroid dysfunctions (hypo- or hyperthyroidism). Also, patients who had ophthalmological problems like glaucoma, retinopathy or retinal surgical history, or macular degeneration were excluded from the study. Additionally, our patients and controls were nonsmokers.

Sincerely,

Dr. Hatice Kose Ozlece

Publisher's note Springer Nature remains neutral with regard to jurisdictional claims in published maps and institutional affiliations.

This reply refers to the letter available at https://doi.org/10.1007/s11325019-01817-3

Hatice Kose Ozlece

haticekse@hotmail.com

1 Department of Neurology, Acibadem Private Hospital,

Kayseri, Turkey

2 Department of Neurology, Private Konak Hospital, Adapazarı, Sakarya, Turkey

3 Medical Faculty Department of Eye Disease, Trakya University, Edirne, Turkey

4 Department of Neurology, Adatıp Private Hospital, Adapazarı, Sakarya, Turkey 